\title{
Bedrock topography and wind erosion sites in East Antarctica: observations from the 2002 US-ITASE traverse
}

\author{
Brian C. WELCH, Robert W. JACOBEL \\ Department of Physics, St Olaf College, 1500 St Olaf Avenue, Northfield, MN 55057, USA \\ E-mail:welchb@stolaf.edu
}

\begin{abstract}
Ice stratigraphy from deep-penetrating radar data collected during the 2002 US International Trans-Antarctic Scientific Expedition (US-ITASE) traverse shows evidence of a significant erosion surface and drift-filled basin related to a previously undiscovered $1400 \mathrm{~m}$ subglacial mountain between Hercules Dome $\left(87^{\circ} 42^{\prime} \mathrm{S}, 108^{\circ} \mathrm{W}\right)$ and South Pole. The $3 \mathrm{MHz}$ radar profile crosses three subglacial mountains at approximately $45^{\circ}$ to the ice-flow direction. Cross-cutting reflectors in the top $500 \mathrm{~m}$ of ice stratigraphy are interpreted as angular unconformities resulting from wind erosion as the ice deforms over the mountain tops. The unconformities correlate locally with zones of high RADARSAT reflectivity. Several nearby sites with similar relatively high RADARSAT reflectivity adjacent to the traverse indicate that active wind erosion may be taking place at these locations as well. Based on the local correlation between surface wind scour and subglacial topography, we interpret the nearby cluster of bright RADARSAT reflectivity to indicate the presence of a small range of subglacial mountains. The ability to trace isochronal stratigraphy, associated with scour sites using shallow and deep radar, to nearby dated ice cores presents the possibility of exploiting wind-scour zones to access well-dated older ice with shallow-coring equipment.
\end{abstract}

\section{INTRODUCTION}

We report here the observations from radio-echo sounding (RES) of several areas of wind scour and deposition correlated with sharp features in subglacial bedrock topography. These areas also coincide with zones of high reflectivity ('brightness') seen in the RADARSAT mosaic (Jezek and others, 2002).

Wind, combined with generally low snow accumulation rates, can cause localized negative accumulation anomalies, even to the extreme of blue-ice zones seen in numerous locations in East Antarctica (Bintanja, 1999). Evidence of recent changes in the activity of blue-ice zones due to ice flow or climate change is also seen in East Antarctica (Siegert and others, 2003). Where wind erosion is less extreme it may nevertheless significantly influence local accumulation rates, such as the megadunes region near the Transantarctic Mountains (Fahnestock and others, 2000).

Identification of accumulation anomalies upstream of icecore locations is critical to dating the ice-core stratigraphy. Similarly, where robust stratigraphic dating is available, wind-scour zones present near-surface exposures of older ice that can be extracted with shallow-drilling equipment.

\section{Data collection and observations}

The US portion of the International Trans-Antarctic Scientific Expedition (US-ITASE) (Mayewski, 2003) presented opportunities to map unexplored regions of the continent (Fig. 1). During the 2002 traverse from Byrd Camp $\left(80^{\circ} \mathrm{S}, 120^{\circ} \mathrm{W}\right)$ to South Pole, the route crossed through the Transantarctic Mountains into East Antarctica.

Low-frequency radio-echo sounding data were recorded with an impulse radar system at a center frequency of $3 \mathrm{MHz}$, designed to maximize signal to noise through realtime stacking and to minimize spatial aliasing due to traverse speeds of up to $14 \mathrm{~km} \mathrm{~h}^{-1}$. A 14-bit digitizing board mounted directly on the controlling computer records data at $100 \mathrm{MS} / \mathrm{s}$ (megasamples $\mathrm{s}^{-1}$ ) and can acquire airwave triggers at up to $300 \mathrm{~Hz}$. This allows the system to stack (average) up to 1700 waveforms for each recorded trace while maintaining a trace spacing of less than a quarter wavelength to eliminate spatial aliasing of steep reflector slopes. Simultaneous kinematic global positioning system (GPS) data provide position information for the RES data (Hamilton and Spikes, 2004). Processing steps include a bandpass filter (corner frequencies 1 and $4 \mathrm{MHz}$ ) to remove ambient and system noise, normal move-out correction to accommodate the constant $135 \mathrm{~m}$ antenna separation, and frequency-wavenumber migration to correct for the finite beamwidth of the antennas. Saturation in the dipole antennas due to the direct arrival of the transmitter pulse generally obscures sub-horizontal stratigraphy to $\sim 100 \mathrm{~m}$ depth. Tilted layers in the near-surface stratigraphy can be enhanced by using a high-pass horizontal filter (subtracting an average trace from the data). Further processing utilizes a linear time-dependent range-gain, and elevation correction derived from the GPS surface elevation data. Additional specifics of the system and processing methods are provided by Welch and Jacobel (2003).

The wind-scour region is located along the 2002 USITASE traverse route between Hercules Dome (core site 02-4), core site 02-5 and the South Pole (Figs 1 and 2). Approximately $33 \mathrm{~km}$ before reaching core site $02-5$, the traverse encountered a local surface hill roughly $100 \mathrm{~m}$ in elevation and $3 \mathrm{~km}$ in breadth. No quantitative measurements of the surface conditions were made, but anecdotal descriptions from traverse team members include the following observations. Surface conditions at the crest of the hill were unusual, with a very hard surface of hummocky terrain (typically $3-10 \mathrm{~m}$ across and $1-4 \mathrm{~m}$ in height) with fresh snow in the valleys. Local gradients were steep enough that sleds of the traverse train slid laterally on the slopes of the hummocks. This is the only terrain covered in 4 years of the US-ITASE traverse that caused the largest sleds to slip 


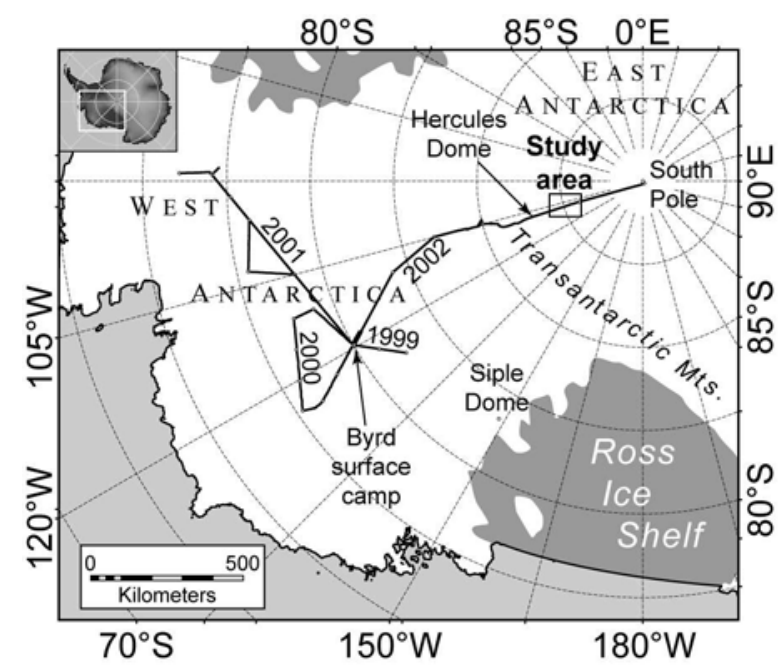

Fig. 1. Map of the 1999-2002 US-ITASE routes in West and East Antarctica, highlighting the study area between Hercules Dome and South Pole.

laterally. In other locations, wind-packed snow was always soft enough for the sled runners to gain lateral purchase. On the whole, this area represented the hardest and roughest surface encountered by the 2002 US-ITASE traverse between Byrd Camp and the South Pole.

The deep radar data reveal that a large bedrock mountain (20 km across, $1.5 \mathrm{~km}$ high) is present directly beneath this surface area (Fig. 3). Although a regional bedrock high (tens of $\mathrm{km}$ across) is depicted in the BEDMAP dataset (Lythe and others, 2001), this appears to be the first direct mapping in the area to resolve individual peaks with this degree of relief. Overall the internal ice stratigraphy in Figure 3 is generally conformable with the bedrock topography, with a few exceptions (e.g. km 87, km 100 and km 150) where deep layers show local thinning and thickening. However, the most striking feature of the internal stratigraphy is a crosscutting reflector that appears just north of the largest bedrock mountain in the near-surface ice (0-600 m depth at km 124128). A similar but smaller feature appears at km 110-115.

An expanded view of this feature is shown in Figure 4 and in the digitized interpretation of Figure 5b. Stratigraphy over the mountain dives beneath the cross-cutting reflector while the layers to the left of the reflector are flat and truncate at the top edge of the reflector surface. The upper portion of the cross-cutting reflector appears to intersect with the ice surface near $\mathrm{km} \mathrm{128.} \mathrm{Below} 600 \mathrm{~m}$ depth, the slope of the reflector flattens and it becomes indistinguishable from the surrounding ice stratigraphy. Close examination of Figure 4 shows that the cross-cutting reflector is made up of a reflector surface that is nearly conformable to the layers beneath. However, the layers above (to the left of) the crosscutting reflector truncate into its upper surface.

Ice flowlines (Fig. 2) were derived from calculated surface slopes based on the regional ice surface topography extracted from the RADARSAT-1 Antarctic Mapping Project (RAMP) digital elevation model (DEM) version 2 (Liu and others, 1999). Comparisons between the DEM and GPS data recorded along the traverse show agreement over large areas such that surface slopes calculated over a few ice thicknesses are representative of the actual surface (Hamilton and Spikes, 2002). The flowlines show that the cross-cutting

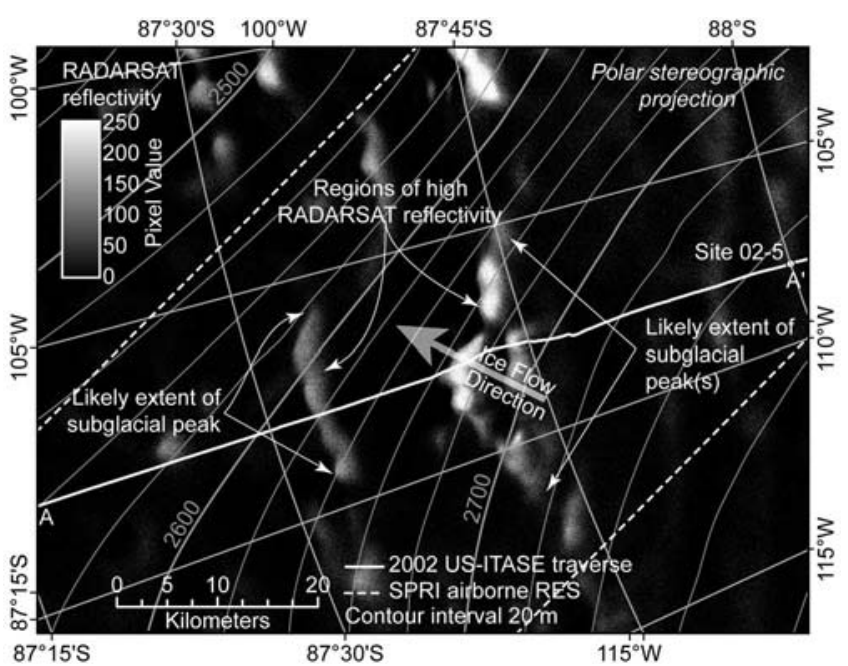

Fig. 2. Map of study area showing traverse route and RADARSAT reflectivity from the $25 \mathrm{~m}$ mosaic by Jezek and others (2002) and ice surface elevation contours (Liu and others, 1999). Local regions of high RADARSAT reflectivity are seen along and adjacent to the traverse route. US-ITASE ice-core site $02-5$ is the location of a $>100 \mathrm{~m}$ ice core. General ice-flow direction (large arrow) at km 128 is assumed to be parallel to the regional ice surface gradient.

reflector is downstream of the mountain, and its apparent intersection with the ice surface is roughly at the crest of the mountain. This suggests a relationship between the crosscutting feature and the ice surface perturbation caused by the bedrock mountain. Such a feature would be advected downstream by subsequent ice flow. The approximately $45^{\circ}$ angle of the traverse route with respect to the ice-flow direction means that the radar data likely captured only a portion of the buried feature.

The $25 \mathrm{~m}$ radiometrically balanced RADARSAT Antarctic Mapping Mission 1 (AMM-1) mosaic (Jezek and others, 2002) shows a region of local high reflectivity directly over the bedrock mountain (Fig. 5a). The continent-wide scaling in the mosaic means that the correlations with our icepenetrating radar data are representative of local features only. Similar areas of locally high RADARSAT reflectivity are seen along and adjacent to the US-ITASE traverse route within a few tens of kilometers of the bedrock mountain and its associated RADARSAT 'bright spot' (Fig. 2).

\section{INTERPRETATION}

We interpret the cross-cutting reflector as an angular unconformity resulting from advection and subsequent burial of a subaerial erosion surface over the bedrock mountains. Ice flow over the bedrock mountain causes a perturbation in the ice surface that increases the local largescale $(>1 \mathrm{~km})$ surface roughness. Wind interaction with the surface topography affects local snow accumulation patterns. The interaction of regional snow accumulation rates, wind patterns and ice flow determines whether local wind erosion may exceed accumulation to result in net ablation by subaerial erosion (Bintanja, 1999).

The vertical continuity of the cross-cutting reflection wavelet indicates that the reflector is a spatially continuous region of differing electrical properties within the ice rather than just an interface between multiple blocks of tilted stratigraphy. The spatial continuity of the reflector shows that 


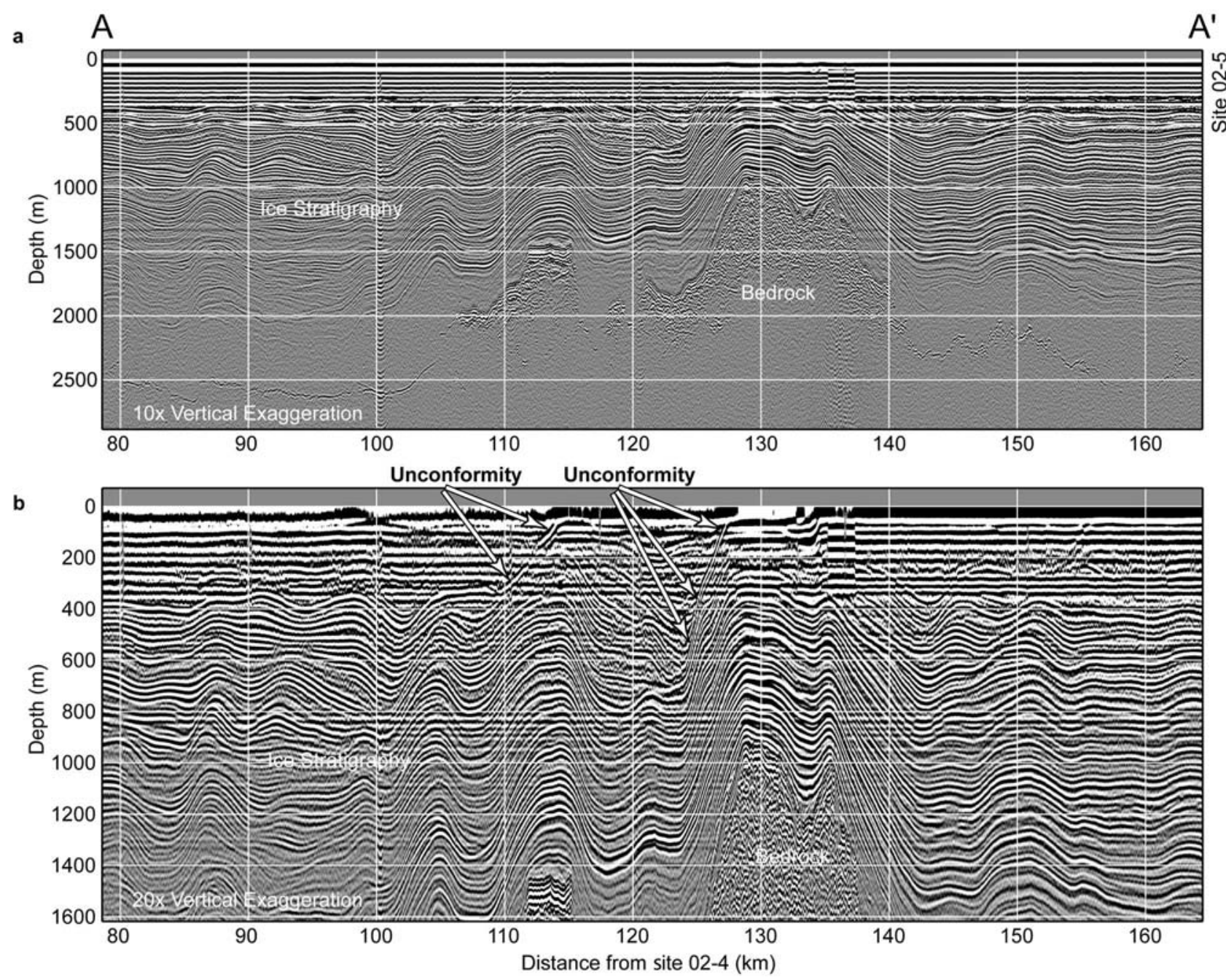

Fig. 3. (a) Processed RES data from profile $A-A^{\prime}$ plotted with $10 \times$ vertical exaggeration. (b) Near-surface stratigraphy shown after horizontal filter to remove much of surface ringing. The strongest two cross-cutting internal reflectors are seen at $\mathrm{km} 115$ and km 128 . The horizontal filter adds some noise at greater depths (e.g. at $825 \mathrm{~m}$ depth).

it is not a result of vertical resolution limitations causing constructive interference between adjacent layers. Rather, the reflector is distinct between the adjacent sub-horizontal stratigraphic layers, perhaps the result of patchy fresh-snow accumulation in the valleys of the hummocky terrain within the scour site. That the reflecting layer has finite thickness becomes apparent in $\mathrm{km} 125.2-126.3$ where we see a second partial wavelet appear beneath the primary crosscutting reflector due to a change in thickness of the reflecting layer that alters the interference of the reflected signal (Fig. 4).

The brightness and continuity of the RES reflector indicates a dramatic change in the electrical properties of the ice. This could result from increased dust/acid concentrations due to locally low snow accumulation at the mountain top or the strong change in firn density as the erosion surface is buried by softer fresh snow. The interface then would be advected and buried downstream of the mountain. Given the hardness of the snow surface over the mountain as experienced by the US-ITASE traverse team, we believe that there is ongoing wind erosion at this site that exposes older firn. Samples of the exposed surface would be required to validate this interpretation.

In addition to the presence of a local high in reflectivity seen in the RADARSAT mosaic upstream of the intersection between the cross-cutting reflector and the ice surface (approximately km 128 in Fig. 3), we note that there are two other, less pronounced areas of relatively strong RADARSAT reflectivity at $\mathrm{km} 115$ and $\mathrm{km} 135$. Although depiction of the near-surface stratigraphy is limited in our data, there are indications of similar but smaller cross-cutting reflections at those sites. At each of the bright RADARSAT locations there are also steeply dipping near-surface reflectors seen in $400 \mathrm{MHz}$ RES data recorded simultaneously during the USITASE traverse (personal communication from S. Arcone, 2004). It should be noted that these sites of moderately strong RADARSAT reflectivity did not exhibit the extreme snow surface conditions seen by the US-ITASE traverse over the largest bedrock mountain ( $\mathrm{km} \mathrm{128)}$.

Two smaller RADARSAT reflectivity peaks at $\mathrm{km} 99$ and km 156 seen in Figure 5 are not associated with bedrock mountains, but the shallow radar data do show hints of tilted near-surface stratigraphy. The RADARSAT response at these sites may be due to a different mechanism.

\section{DISCUSSION}

With our interpretation of the reflector as an artifact of a paleo- and ongoing erosion feature, we may examine the 


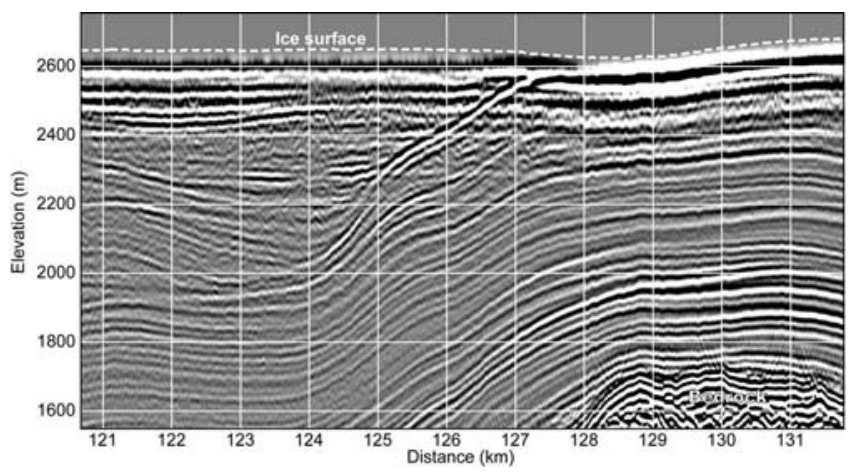

Fig. 4. Close-up of cross-cutting reflector seen in elevation section of $3 \mathrm{MHz}$ radar data. The reflector is nearly conformable to deeper layers but cross-cuts overlying stratigraphy, leading to the interpretation as an angular unconformity. The top of the basal mountain is seen at the lower right. Vertical exaggeration is $5 \times$.

implications of such a feature on the interpretation of wellmapped stratigraphy downstream of the bedrock mountain. Ice flows over the subglacial mountain, and the resultant change in ice surface topography modifies the local accumulation pattern (Bintanja, 1999). Subsequent advection by ice flow and burial through snow accumulation preserves these spatial accumulation patterns as perturbations in the internal ice stratigraphy and provides a record of surface conditions at the time of burial (Fig. 6). By definition, an angular unconformity is a buried erosion surface. Unlike most geologic settings, however, this unconformity does not represent a single large-scale erosional event in the past, but rather a record of a relatively small-scale region of continual erosion that extends from the present (the surface intersection) into the past.

The development of the erosional surface depends upon the proper combination of ice surface roughness (caused by ice flow over the subglacial mountain), regional accumulation rates, and wind strength (prevailing winds and/or dominant storm tracks). The unconformity itself is a result of advection due to ice flow and is therefore always downstream of the erosional surface (Fig. 6). Therefore, changes in the geometry of a buried unconformity are indicative of changes in ice flow. Note that the deep onlap stratigraphy shown in Figure 6 is nearly parallel to the original stratigraphic layers. Since the scour surface itself may not be an actual RES reflector at depth, the similarity in stratigraphic configuration may be interpreted incorrectly as continuous deposition.

A hypothetical study that completely maps a buried unconformity along and perpendicular to local ice flowlines (a three-dimensional profile grid) would yield information about the accumulation rate and ice-flow history over the bedrock mountain. Such a study would be particularly useful in a region such as this site where paleoclimate and post-Last Glacial Maximum (post-LGM) ice-flow information is lacking. The nearest deep ice-core sites are Byrd Camp and Vostok. In addition, climate models benefit from additional constraints on surface climate conditions (e.g. onset of wind erosion due to reduced accumulation or thinning of the ice sheet over a subglacial mountain).

The oblique orientation of the US-ITASE radar profile with respect to the ice-flow direction precludes a straightforward

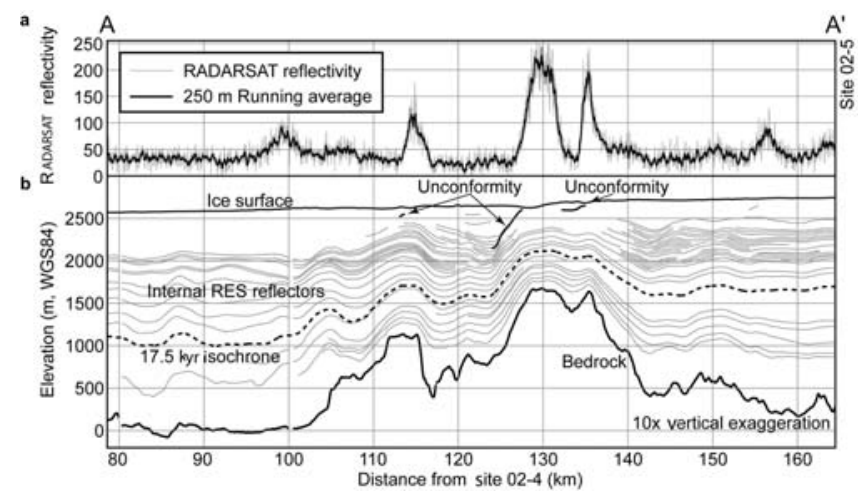

Fig. 5. (a) Interpolated RADARSAT reflectivity values from profile $A-A^{\prime}$. The RADARSAT data were smoothed with a $250 \mathrm{~m}$ running average. (b) Interpretation of RES data along profile $\mathrm{A}-\mathrm{A}^{\prime}$ ending at ice-core site 02-5. Data were geolocated and elevation-corrected using concurrent precision GPS measurements. The bedrock topography (heavy black line) shows a large bedrock mountain approximately $1700 \mathrm{~m}$ in elevation. Internal stratigraphy (thin gray lines) is generally conformable to the bedrock topography and ice surface. A prominent angular unconformity intersects the ice surface near km 128.

interpretation of paleo-ice flow from the unconformities. Similarly, we cannot accurately estimate the longevity of erosion activity at this site, though it has persisted at least since the age of the deepest truncated layer in our RES data. The oldest (deepest) extent of the unconformity in our data is post-LGM, based on comparison to dated stratigraphy near Byrd Camp (Jacobel and Welch, 2005). However, since the RES profile does not follow the unconformity to its downflow extent, we cannot put an upper limit on the period of active erosion at this site.

Stratigraphic dates to be developed from the site 02-5 ice cores, along with shallow RES data recorded by USITASE colleagues will allow us to date the exposed ice in

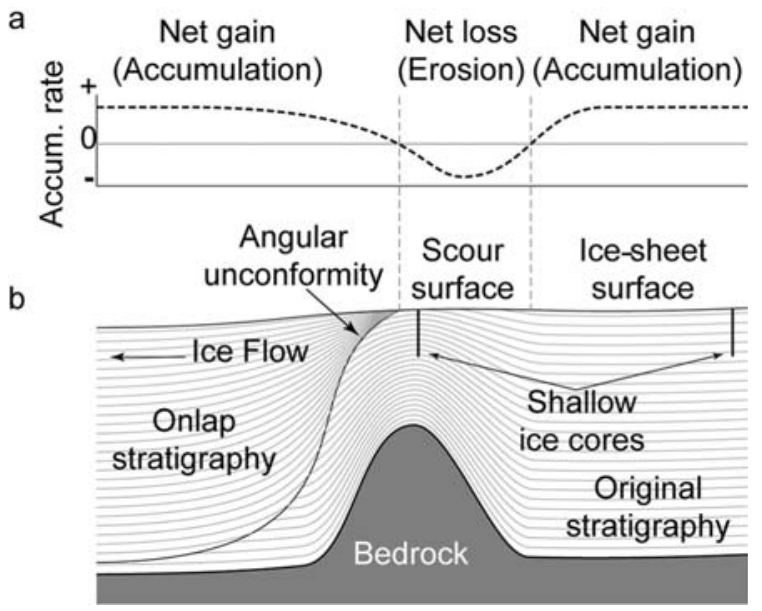

Fig. 6. (a) Hypothetical accumulation rate distribution (heavy dashed line) over an ice surface rise caused by ice flow over a large bedrock mountain. (b) Cartoon of along-flow ice stratigraphy over a bedrock mountain where erosion of surface snow causes an unconformity that is subsequently advected and buried downstream. A shallow ice core at the scour zone could access older ice than the well-dated core located upstream. The age-depth relationship of the pristine upstream core is tied to the scour core using RES profiles. 
the scour zone. Initial interpretations of shallow $400 \mathrm{MHz}$ radar data from the US-ITASE traverse show that ice loss at the site is likely $<100 \mathrm{~m}$ (personal communication from $\mathrm{S}$. Arcone, 2004). Therefore, based on modern accumulation rates of $0.18 \mathrm{~m} \mathrm{a}^{-1}$ (ice equivalent) measured at Hercules Dome (Jacobel and others, 2005), we estimate that the age of any exposed ice is less than a few hundred years old. We expect the ice core acquired at site 02-5 to overlap the age of the exposed erosion surface. Improved dating control from that core, along with a detailed interpretation of the shallow-ice-radar data, will provide better constraints on the thickness of ice loss and the age of the exposed surface.

We see an intriguing potential application of these shallow scour sites for programs of shallow-ice-core recovery $(<200 \mathrm{~m})$. High accumulation rates are desirable to increase time resolution of ice-core data, but this also limits the maximum age for shallow ice cores. Exposure of old ice at the surface in regions of wind scour could allow shallow coring operations to obtain older ice than is normally possible. The difficulty lies in accurately dating the exposed surface of the scour site.

Strong age control available through modern ice-core processing (Kaspari and others, 2003) and the isochronal nature of RES stratigraphy allow shallow ice cores to be correlated over tens of kilometers (Spikes and others, 2004). Shallow and deep radar data could extend age control from a second core taken upstream in undisturbed snow to the core taken within the scour zone. Thus two cores of similar length and ease of extraction would produce a longer record of local conditions. Where correlations exist between the scour zones identified in RES data and satellite imagery, it may be possible to locate other nearby scour sites that could be cored and dated with the RES stratigraphy.

\section{ACKNOWLEDGEMENTS}

We thank our colleagues on the US-ITASE traverse and acknowledge the support in the field of those from Raytheon Polar Support Corporation. We also thank H. Björnsson, O. Eisen and an anonymous reviewer for helpful comments on the manuscript. Development of the radar system software and assistance with the data processing was provided by several undergraduates in the Physics Department at St Olaf College, particularly M. Bills, K. Christianson,
K. Cofell-Dwyer, M. Helgen and L. Smith. This work was supported by US National Science Foundation grant No. OPP-9814574.

\section{REFERENCES}

Bintanja, R. 1999. On the glaciological, meteorological and climatological significance of Antarctic blue ice areas. Rev. Geophys., 37(3), 337-359.

Fahnestock, M.A., T.A. Scambos, C.A. Shuman, R.J. Arthern, D.P. Winebrenner and R. Kwok. 2000. Snow megadune fields on the East Antarctic Plateau: extreme atmosphere-ice interaction. Geophys. Res. Lett., 27(22), 3719-3722.

Hamilton, G.S. and V.B. Spikes. 2004. Evaluating a satellite altimeter derived digital elevation model of Antarctica using precision kinematic GPS profiling. Global Planet. Change, 42(1-4), 17-30.

Jacobel, R.W. and B.C. Welch. 2005. A time marker at $17.5 \mathrm{kyr}$ BP detected throughout West Antarctica. Ann. Glaciol., 41 (see paper in this volume).

Jacobel, R.W., B.C. Welch, E. Steig and D. Schneider. 2005. Glaciological and climatic significance of Hercules Dome, Antarctica - an optimal site for deep ice core drilling. J. Geophys. Res., 110(F1), F01015. (10.1029/2004JF000188.)

Jezek, K. and RAMP Product Team. 2002. RAMP AMM-1 SAR image mosaic of Antarctica. Fairbanks, AK, Alaska SAR Facility, in association with the National Snow and Ice Data Center, Boulder, CO. Digital media.

Kaspari, S.D., P.A. Mayewski, D.A. Dixon and S.B. Sneed. 2003. Climate variability in West Antarctica derived from marine aerosol species from ITASE firn/ice cores. [Abstract C11B-0809.] Eos, 84(46). Fall Meet. Suppl., F348.

Liu, H., K.C. Jezek and B. Li. 1999. Development of an Antarctic digital elevation model by integrating cartographic and remotely sensed data: a geographic information system based approach. J. Geophys. Res., 104(B10), 23,199-23,213.

Lythe, M.B., D.G. Vaughan and BEDMAP consortium. 2001. BEDMAP: a new ice thickness and subglacial topographic model of Antarctica. J. Geophys. Res., 106(B6), 11,335-11,351.

Mayewski, P.A. 2003. Antarctic oversnow traverse-based Southern Hemisphere climate reconstruction. Eos, 84(22), 205, 210.

Siegert, M.J., R.C.A. Hindmarsh and G.S Hamilton. 2003. Evidence for a large surface ablation zone in central East Antarctica during the last Ice Age. Quat. Res. 59, 114-121.

Spikes, V.B., G.S. Hamilton, S.A. Arcone, S. Kaspari and P. Mayewski. 2004. Variability in accumulation rates from GPR profiling on the West Antarctic plateau. Ann. Glaciol., 39, 238-244.

Welch, B.C. and R.W. Jacobel. 2003. Analysis of deep-penetrating radar surveys of West Antarctica. Geophys. Res. Lett., 30(8), 1444. (10.1029/2003GL017210.) 